\title{
An Overview on Tall Buildings from The Point of Structural Engineering
}

\author{
İsa YÜKSEL
}

Bursa Technical University, Department of Civil Engineering, 16330 Yıldırım, Bursa

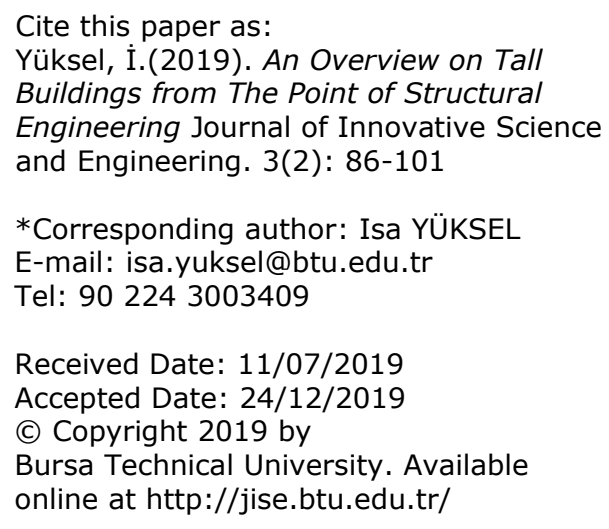

\section{(i) (8)}

The works published in Journal of Innovative Science and Engineering (JISE) are licensed under a Creative Commons Attribution-NonCommercial 4.0 International License.

\begin{abstract}
Tall building construction has increased rapidly in Turkey especially in metropolitans such as Istanbul, Ankara, and Bursa. These buildings are subjected to different kinds of loads during its construction and service life time. Substantial load types affecting to tall buildings are gravity loads, seismic and wind loads, and other special loads. Modern lightweight and high strength materials, new force resisting structural systems, shock absorption systems, structuring combinations reveals different solutions to engineers and architects for design and constructing tall buildings. The aim of this paper is to review structural form, wind and earthquake loads on tall buildings from the point of structural engineering. At first, the effect of building form to building aerodynamics is examined. Then the loads, selection and arrangement of the major structural elements to resist loading combinations containing gravity, earthquake, and wind loads on tall buildings are discussed. In addition, the new provisions are reviewed that given in TBEC-2018, which is the first national code comprised special regulations for tall buildings in Turkey.
\end{abstract}

Keywords: Building Form, Design, Earthquake, Tall Buildings, Wind. 


\section{Introduction}

Human beings have built edifices throughout history for different reasons. Today's skyscrapers are built as symbols of power, wealth and prestige. Parallel to the rapid urbanization in major cities in Turkey tall building construction has increased significantly. The majority of these high-rise buildings consists of cast in place reinforced concrete structural systems. Today tall buildings are highly sophisticated engineering projects. Due to the complexity of these structures, engineers and architects need to use the most advanced design techniques [1]. In order to design an efficient and economical tall building, the design team should have a thorough understanding of the important factors affecting the structural system selection process. Also they should have a knowledge of how the structural system will interrelate with other aspects such as architectural and mechanical aspects. Structural engineers take part at the core of the design process for tall building projects.

Tall buildings were generally designed to use as offices at the beginning of the twentieth century. Today, in almost all major cities in the world, tall buildings are constructed for different reasons such as office, residence, etc. Some of these buildings are generally accepted as symbol of the city in many countries. Besides, many people accept tall buildings as an inevitable feature of urban development. Reflections of this trend in the world is observed in Turkey too. The number of tall building construction have increased more and more in metropolitans like Istanbul and Ankara in the last 20-30 years. Earthquakes in Turkey are known to cause significant damage to buildings. Many buildings have been destroyed or damaged in past earthquakes, and many have suffered casualties. As high-rise buildings enter our lives, it is a necessity to take into account all kinds of risks that may occur due to earthquakes. Similarly, according to geographical and local conditions, wind is an important factor in this sense just like an earthquake. Structural design against wind loads is also important for the comfort of the structure. On the other hand, more emphasis is needed on the fire as building heights increase. In this context, the issue of fire in high-rise buildings is also of great importance. Therefore, high-rise structures are different in terms of design and construction techniques as compared to low-rise and medium-rise buildings. Design teams needs having expertise in analysis and design for wind, earthquake, and fire effects. On the other hand, tall buildings have many effects in the region from traffic to infrastructure, to the climate of the city. Many issues such as cladding systems, vertical circulation in the building, parking lots, heating, ventilation, lighting, elevators, electricity and communication installations should also be addressed. Tall buildings are structures that have a great impact on the environment and people as well as large investments. Even the social and psychological effects of these structures should be taken into account. An optimum solution is sought by considering all of this by the design team during the design process. Computer-aided design technologies provide convenience in architectural and structural design of tall buildings in today. This fact provides freedom in architectural and engineering design processes. However, the building forms used in design were restricted in the past due to materials and technological limitations. Yet innovations and developments in construction techniques and material technologies have made it easy today to design and build tall buildings. As the building height increases and structural forms are diversifying static and dynamic load effects have become more important in time. Therefore, more sophisticated engineering analyses and high technologies are needed at the present time. 
An overview from the point of structural engineering is presented in this paper. Structural forms, wind and earthquake effects on tall buildings, and new national building earthquake code provisions about earthquake-resistant design rules is addressed. Also, it will be pointed out to some important aspects and guiding principles in structural design that would be useful for structural designers.

\section{Tall Building Concept and Structural Forms}

\subsection{Definition of Tall Building}

A 'tall building' or 'high-rise building' is a building whose height creates different conditions in the design, construction and use than those that exist in common buildings of a certain region and period [2]. One definition is that if the building aspect ratio, height divided by lowest overall lateral dimension, is more than 5:1, then the building may be considered tall [3]. The tallness of a building is a matter of a person's or community's perception. There is not a particular definition of a tall building and also there isn't a general concencus in terms of maximum height or maximum number of story in order to define a building as "tall building" and "super tall building". The general criteria for a building to be accepted as a tall building is that different design and construction rules should be followed because of the building's height. In fact, the definition of tall building is rather subjective. Even different approaches are exist for the height measurement of the building. A building is defined as high-rise when it is considerably higher than the surrounding buildings or its proportion is slender enough to give the appearance of a tall building [1]. According to CTBUH (Council on Tall Buildings and Urban Habitat), tall buildings can be divided in three categories. Buildings which have more than 14 storeys or buildings higher than 50 meter categorized as "high buildings". If the building height is in between 300-600 meters then it can be categorized as "supertall building". Lastly, the buildings which have more than 600-meter height is categorized as "mega tall buildings". According to Emporis [4] that is a global provider of building information, a high-rise building is a structure whose architectural height is between 35 and 100 meters. A skyscraper is defined by Emporis as a multi-story building whose architectural height is at least 100 meters. The skyscraper center of CTBUH has lists that shows countries ranked by total number of completed buildings. The first three countries are United States of America, China, and Canada in this list. Turkey, with 8 buildings higher than 200 meters, is ranked as the 17 th on this list.

Since the concept of tall buildings contains relativity then there is not a unique definition of tall buildings. The Home Insurance Building that is considered as the world's first skyscraper in 1885 and built in Chicago in United States was only 12-storey and 55 meters high. It is considered as the first steel framed gravity system used in high-rise construction. However, nowadays these buildings are not considered as high buildings in the United States and in many countries. Generally, application of different design and construction rules are additional criteria in addition to basic height criteria in order to identify high buildings. The renewed version of Turkey Building Earthquake Code (TBEC-2018) [5] provides three different height limit according to earthquake design class (EDC) for high buildings. Table 1 shows height limits for definition of high buildings according to TBEC-2018. Certainly, this classification serves in terms of the design rules for earthquake loads. 
Table 1. Height limits for definition of tall building in TBEC-2018

\begin{tabular}{ll}
\hline EDC & Height $(\mathrm{m})$ \\
\hline $1,1 \mathrm{a}, 2,2 \mathrm{a}$ & $\geq 70$ \\
\hline $3,3 \mathrm{a}$ & $\geq 91$ \\
\hline $4,4 \mathrm{a}$ & $\geq 105$ \\
\hline
\end{tabular}

\subsection{Tall Building Structural Systems}

Tall building structural systems have been improved and diversified over time. They began from rigid frame systems and too many new structural forms have emerged up to date. For higher structures, in the early twentieth century, only gravitational loads were involved, and then design techniques were developed for dynamic effects such as earthquakes and wind. Today, design methods are being developed against factors such as impact and blast loads. It is possible to classify the buildings based on the materials used in their structural systems as steel, reinforced concrete, and different types of composites. In the beginning of twentieth century, steel was the most favorite material. While steel was used as structural system material of the first high-rise building in the world, nowadays it is often used as high-performance reinforced concrete, high-strength steel, composite materials, or combinations of these materials, due to evolution over time in concrete and composite technologies. Composite systems use advantages of concrete and steel that advantages are rigidity and fire-resistance of concrete and high tensile strength of steel. Taipei 101 skyscraper, the world's tallest with a height of 508 meters, could be shown as a good example of composite structural system.

Tall building structural systems classified as follows [6].

rigid frame systems

flat plate/slab systems

core systems

shear wall systems

shear-frame systems

- shear trussed frame (braced frame) systems

- shear walled frame systems

mega column (mega frame, space truss) systems

mega core systems

outriggered frame systems

tube systems

- framed-tube systems

- trussed-tube systems

- bundled-tube systems.

Rigid frame systems, flat plate/slab systems, shear wall systems, and core systems are widely used for tall buildings of 40 storeys and below. However, for the very high buildings such as supertall buildings and skyscrapers over 40 storeys 
shear-frame systems, mega column systems, mega core systems, outriggered frame systems and tube systems should be selected. Because lateral drift limits due to wind or earthquake loads should not be exceeded. Limiting tower drifts to acceptable levels is important to the overall performance of the tower [7]. The limit of lateral drift is accepted as approximately $1 / 500$ of the building height for supertall buildings and skyscrapers over 40 stores. Excessive inter-story drift can have adverse impacts on architectural finishes and building façade systems.

Tall building design involves all of the design interfaces present in low-rise construction. Additionally, there are also a number of key factors such as influence of lateral loading which structural engineers in design team must consider. Earthquake and wind loadings govern the design and sizing of many of the main structural elements, particularly core walls and columns. Moreover, in tall buildings, lateral displacement must also be calculated and need to be limited. Excessive lateral displacement may potentially affect secondary elements such as finishes, internal partitions and outer cladding, especially when inter-story drift is too high. This situation shows that there is a close relationship between the structural system and architectural design in tall building design process. Structural form and the function of the building is connected to each other. Building façade and interior use of the building that is a part of architectural design is affected by selection of structural system which is an engineering process. Economy and availability of construction materials to be used in selected systems have also important impacts on the selection of structural system.

A rigid frame is characterized by flexure of beams and columns and rotation at the joints. When frames located at the building exterior an efficient frame behavior can be developed by providing closely spaced columns connected with deep beams to each other. The advantages of a rigid frame are the simplicity and convenience of its rectangular form. Its unobstructed arrangement, clear of structural walls, allows freedom internally for the layout and externally for the fenestration. Stiffness and height of the building could be increased if rigid frame is combined with shear walls [8].

The connection of structural elements with each other has importance in highly seismic zones. Ductile behavior could be achieved by means of plastic hinges formed on beam and column end sections. The system shows post-elastic behavior with huge amount of energy consumption at these plastic-hinged sections. Behavior of these systems must obey "strong columns-weak beams" principle. The disadvantage of these systems is reduction of comfort and increase of damages in non-structural components with great lateral displacements.

Core system is widely used to constitute a reinforced concrete structural system. The core of a tall building is arguably the most important element under consideration during the design process. By introducing a core in the rigid frame system the lateral resistance of the building increases significantly. Rigid frame reacts to the lateral loads by bending beams and columns. This behavior results in large lateral drift of building of a certain height. Core increases flexural, shear and torsional rigidity of the system. Because of architectural reasons, the core could be open or partially open. There are slabs and beams connected to core at each storey (Fig.1). The connection of floor slabs to core could be in the form of a full console (Fig. 2.a) or a half-console that has discontinuous columns on edges of slab (Fig. 2.b). In cantilever slab systems (Fig. 2.a), it is the slab that decides the size of the building which has column free area. 
Structural form is one of the biggest factors that affect structural behavior and aesthetics of tall buildings. Building form and structural system are affected by each other. It is a complex task to enhance the most appropriate form in terms of architectural, structural and aesthetic ways. Geometry and building form have the most important role in the emergence of structural system. On the other hand, there is a close relationship between the form of the structure and building aerodynamics. We should prefer wind-resistant design in order to minimize the negative effect of wind. Today, design of free-form wind resistant tall building is relatively easier with computer-aided design. Wind loads on the structure could be reduced by selecting aerodynamic building forms. In this context, cylindrical, elliptical, tapered or twisted forms can be considered as effective building forms [6]. For example, cylindrical form has less building facade area perpendicular to the wind than that of the area of prismatic forms. Furthermore, because of prismatic forms contain the corner effect; it is obvious that curved surface will be more advantageous.

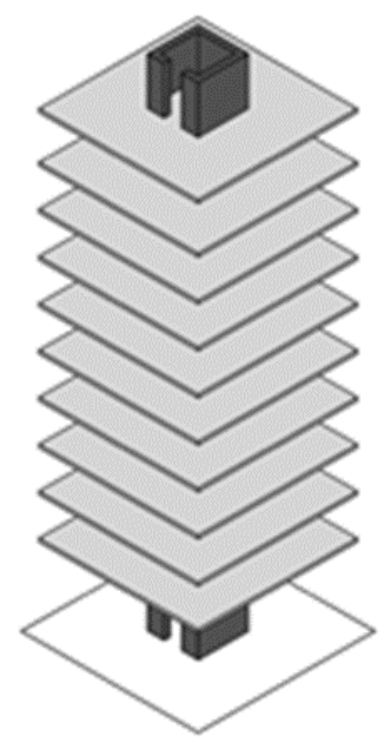

Figure 1. Core and floor slabs around it [6]

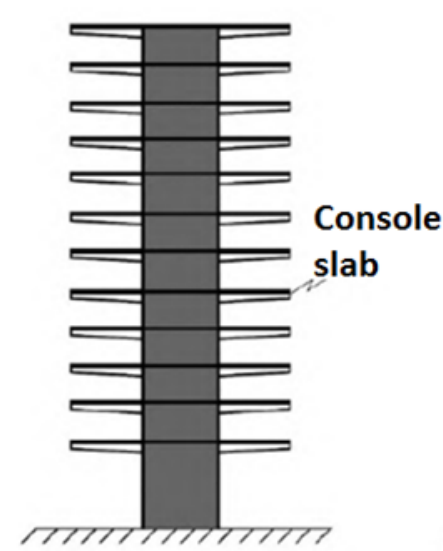

(a)

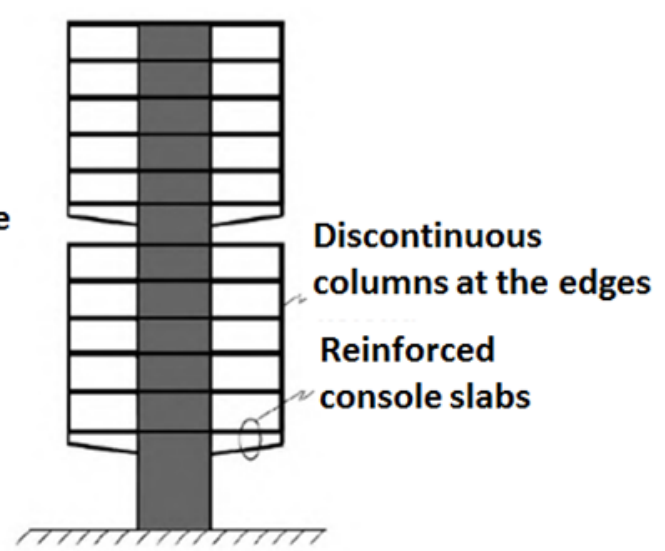

(b)

Figure 2. Floor slabs connected to console. (a) Console floor slabs, (b) Reinforced console slabs [6] 
Building form and structural system have become inseparable and complementary. In general, the tall building form is tackled regarding shape and size, stability, durability, simplicity, efficiency and economy, lightness and delicacy. In choosing the building form; many architectural features and common culture, properties and technology of structural system, regional features, core systems and solutions of them have been effective [9]. The role of the architect in the selection of the building form, the role of the structural engineer in the selection of the building skeleton system is greater. The chosen form will have an effect on the structural behavior and aesthetics of the building. This is why the harmony between architect and structural engineer is so important. High-rise building forms, with various combinations of basic geometric shapes with symmetrical plan, helps to ensure balance and stability of the building. Tall building forms could be prismatic, ever-narrowing, or in another form according to vertical mass distribution. There are four main forms, as follows, which are often used depending on the vertical axis of the building:

Ever-narrowing forms

\section{Twist forms}

Curvilinear forms

Varying cross-section forms

The shape of the buildings significantly affects the wind forces on it and the resulting motion. Building aerodynamics deals with wind forces acting on building and determination of pressures acting on the surfaces of the building. Since square of basic wind velocity is used in calculation of wind pressure on the building, wind pressure increase incrementally as wind velocity increases. Therefore, an appropriate building form should be chosen in order to minimize wind forces that will influence architectural design stage. The dynamic wind pressure produces sinusoidal or narrowband random vibration motions on the building in both along- and across-wind direction as well as rotation about the vertical axis. The main wind affects in along-wind direction that wind creates large overturning forces (Figure 3). In Figure 3, A denotes static loads, B denotes low-frequency dynamic loads, and C denotes resonance component of dynamic load. In addition to these forces a torsional effect of wind should be considered. Especially, cross-wind effect can cause vibration that reduces comfort. The resulting stresses cause damages on the exterior claddings, structural and non-structural elements. For the comfort of people who use the building, the effects of cross-wind must be considered in choosing suitable form and structural system for the tall building [10].

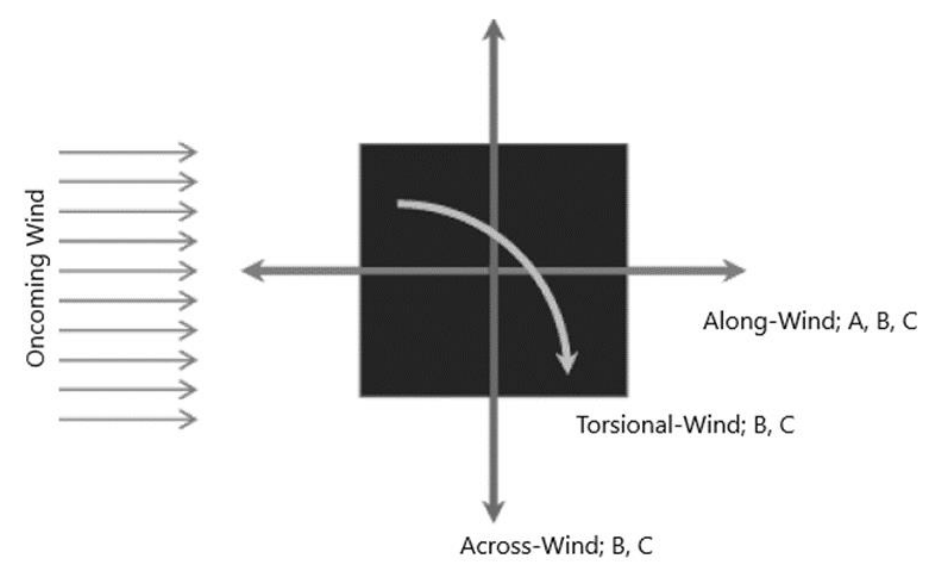

Figure 3. Wind-induced forces on the building cross-section. 
The slenderness ratio of the building is larger, the building is lankier, the lateral displacements of building under earthquake load is greater. The overturning effect caused by earthquake load will get high value, so tensile and compressive stresses due to huge overturning moment in frame elements and foundations are difficult to handle.

Differential shortening of vertical elements such as reinforced concrete columns or walls under gravity loads could affect the design of tall buildings. Especially reinforced concrete columns are critical for differential shortening because of their axial stresses are very high as compared to shear walls. The differential column shortening can be reduced by improving material and structural characteristics of the structural system. Connecting columns with rigid-jointed horizontal members, such as stiff beams and outriggers, and placing additional reinforcement at the column sections could reduce differential shortening of columns [11].

\section{Loads on Tall Buildings}

The main loads affecting tall buildings are gravity loads (dead and live loads), dynamic loads (earthquake, wind, blast, impact etc.), snow and ice loads. Among these loads, dead loads, earthquake loads and wind loads are the most important loads governing the design of the buildings. In addition to these loads, temperature, creep, differential shortening of elements also can create load effects. There are far-reaching national or international qualified regulations for the earthquake-resistant design of tall buildings in most of the countries in the world. Wind loads are as important as earthquake loads for design of tall buildings. Wind-load can be divided into both static and dynamic loading depending on the time period. For long periods of time, the load can be accepted as static load, but for shorter time periods, it can be accepted as dynamic load. The motion of a tall building subjected to action of wind flow occurs primarily in along wind, across wind, and torsional modes of action. Drag force of wind which creates along wind motion acts in the direction of the mean wind (parallel wind). The along wind motion primarily results from pressure fluctuations on windward and leeward face [12]. The across wind response that can be described as a motion in a plane perpendicular to the direction of wind often dominates over the along wind response. In general, tall buildings are sensitive to across wind motion. As wind speed increases, the sensitivity of the building to across wind motion is increases. Wind creates usually maximum lateral load and deflection in the along wind direction. However, the maximum acceleration of a building loading to possible human perception of motion or even discomfort may occur in across wind direction [8]. Wind tunnel measurements have thus served as an effective alternative for determining across-wind and torsional loads.

Vortex-shedding phenomenon has important effects on tall buildings. Wind forces produced on transverse sides of the building are called vortices. When the vortices are shed alternately both of these transverse sides at high speeds then an impulse is generated. This shedding of vortices generate vibration on the building when the speed of wind is high.

The importance of wind loads with respect to building height is shown in Figure 4. It is clear that as building height increases importance of wind loads increases too. Generally, wind loads are accepted as static loads in low-rise or medium-rise structures. However, they should be considered as dynamic load for tall structures. These loads could induce a resonance case in natural frequency of the structure depending the height and slenderness ratio (h/d) of the 
building. Light-bodied building elements used to decrease the mass of the building are affected too much from wind loads in modern tall buildings. As it is difficult to estimate and account of wind loads, comfort conditions due to wind loads are separate issues to consider in tall building design. In fact, wind loads affecting on a tall building could be tackle as sum of static and dynamic loads. Forces and displacements generated from static component of total load could be stated by static analysis methods. Since the wind turbulence changes over time and shows random properties, the dynamic part of wind load effect can be defined using statistical methods and the forces and displacements generated from this part can be calculated using analysis techniques based on Random Vibration Theory [13].

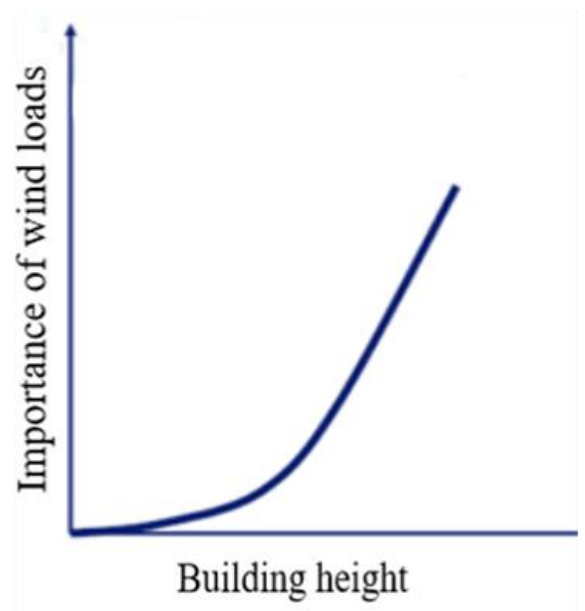

Figure 4. Alteration of wind load importance with respect to building height

Wind speed for any location where the tall building will be constructed must be modeled in order to consider wind loads in design of tall buildings. Wind speed could be shown as sum of static and dynamic components for any point (Equation $1)$.

$V(z, t)=V_{m}(z)+w(z, t)$

Where $\mathrm{V}(\mathrm{z}, \mathrm{t})$ is total wind speed as a function of time and height $\mathrm{z}$ measured from the ground. $\mathrm{V}_{\mathrm{m}}(\mathrm{z})$ is the static component of wind speed that is called average (static) wind speed. It shows the average wind speed for a selected time interval. This component is determined by multiplying surface roughness and topography coefficients to basic wind speed in many codes. The basic wind speed $\mathrm{V}$, corresponds to a 50 year mean recurrence interval and it is measured at $10 \mathrm{~m}$ above ground in Exposure $\mathrm{C}$ as a 3 -second gust speed. $\mathrm{w}(\mathrm{z}, \mathrm{t})$ is the speed variations around the average value (turbulence) that expresses the dynamic wind speed [13]. Effect of dynamic wind load of buildings using equivalent static loads approach are taken into account in the regulations. At first, total lateral displacement is determined caused by static and dynamic wind loads. Then an equivalent static wind load is determined that load will cause equal lateral displacement with the total lateral displacement. The factor increasing static load is called turbulence effect.

Dynamic properties of vibrations due to wind load on the structure should be determined because of comfort criterion. Detailed dynamic analyses are needed for this operation. For example, vortex shedding is considered by adjusting the stiffness and other dynamic properties of the high building such that the frequency of vortex shedding does not 
correspond to the natural frequency of the structure. Otherwise high amplitude vibrations could be occurring which vibrations decreases comfort conditions. The average upper limit of acceleration determined with the 10 years' wind data is $0.015 \mathrm{~g}$ for residence type high-rise buildings in United States. Unfortunately for Turkey, no such upper limit value has been determined. It should be noted that the perception level for human being is that about $0.005 \mathrm{~g}$ to $0.015 \mathrm{~g}$. Therefore, peak acceleration at the top floors of the building resulting from frequent windstorms should be limited to minimize possible perception of motion by the occupants. In order to mitigate cross-wind effect structural designer should take some precautions such as using variable cross-section, rounded corners, aerodynamic top solutions etc.

Since high-rise buildings are getting taller and slenderer, their structural design becomes increasingly influenced by specific behavioral factors that are much less significant for shorter buildings. These factors include the dynamic response of tall buildings to wind loads both in the ultimate and serviceability limit states, and the differential axial shortenings of the vertical elements of under gravity load effects [14]. The overall slenderness ratio of a tall building is usually defined by the ratio of height of the building to its narrowest plan dimension. This ratio has a great influence on the magnitude of the dynamic wind response. When the overall slenderness is high and natural frequency is low then a dynamic wind response is expected from the building.

Besides structural system design, the design of the tall buildings should contain other issues such as fire, sustainability, urban design, and architectural factors. These factors are as important as wind or earthquake. Although some other general purpose codes or regulations involves special provisions for wind loads and fire, it is clear that these provisions could not be enough for tall buildings of today. Fortunately, relevant European codes can be used in Turkey in addition to national codes for the wind effects. Even better, special national codes about these factors should be prepared. A desperate situation could be formed in tall buildings in case of necessary precautions are not taken about fire resistant design, fire escape and rescue issues. This topic is so extensive that; the fire rating of the material, gas evacuation and fire extinguishing systems, the fire rating of the structural system, fire escapes and rescue systems, contains many important subheadings.

Earthquake motions produce horizontal and vertical seismic loads on structures. The effect of horizontal forces is very dominant compared to the effect of vertical forces. These horizontal forces generate axial forces, bending moments, torsional moments, and shear forces on structural elements. The aim of seismic design is to ensure that a structure behaves satisfactorily when subjected to earthquake loading. Since traditional codes do not deal with the non-linear behavior of the structures, they are not suitable for the seismic design of tall buildings. Earthquake motions produce horizontal and vertical seismic loads on structures. These forces generate axial forces, moments, and shears on structural elements. For tall buildings, a performance-based design approach is preferred where two or more different levels of response is considered. For instance, EC8 establishes two fundamental requirements. However, the CTBUH guidance document (Recommendations for the Seismic Design of High-Rise Buildings) [15] considers three levels of ground motion with different expectations. Both the EC8 and CTBUH approaches entail precise definition of the deformation limits and related level of damages expected for each level of performance [3]. 


\section{Special Code Provisions of TBEC-2018 For Tall Buildings}

A special chapter (Unit 13: Special Rules for Structural Design of Tall buildings subjected to Earthquake Effect) is reserved in TBEC-2018 [5] for the first time that chapter involves special design rules for high-rise buildings subjected to earthquake action. These special provisions are given only for the reinforced concrete and steel high-rise building structural systems subjecting earthquake loads. Furthermore, the major innovation in the TBEC-2018 [5] is obligation of getting service of supervision and control of design by an expert for special issues from beginning to the end of the project.

The scope of the aforementioned chapter is to reveal special design rules for reinforced concrete and steel high-rise buildings subjected to earthquake effect. The limit of tall structures which are changing with respect to Earthquake Design Category (EDC) were shown in Table 2. All tall building structural systems must be arranged as "high ductility level" except some buildings whose EDC is equal to 4. Behavior properties of structural members of tall building structural systems are defined in the code. These are deformations corresponding to nonlinear ductile behavior and internal forces corresponding to linear behavior. For reinforced concrete structural walls, steel or reinforced concrete frames having high ductility level, nonlinear ductile behavior could be assigned in application of capacity design principles.

The special unit of TBEC-2018 [5] for tall buildings follow the performance based design (PBD) approach which has been introduced to earthquake engineering society in last decade. Earthquake Ground Motion Levels (EGML) in the code is defined in four levels which are shown as follows:

EGML-1: Probability of exceedance in 50 years is $2 \%$

EGML-2: Probability of exceedance in 50 years is $10 \%$

EGML-3: Probability of exceedance in 50 years is $50 \%$

$>$ EGML-4: Probability of exceedance in 50 years is $68 \%$.

The structural design of tall buildings must be completed in three stages which are shown as follows;

Design Stage I: This is a preliminary design phase under the effect of EGML-2 earthquake in order to provide controlled damage performance target by using strength based design principles. Vertical loading calculations including construction stage analysis, wind load analyses, and creep calculations for reinforced concrete elements should be completed at the beginning of this phase. In design stage I, minimum base shear force calculated from Equation 2 must be taken as a basis.

$V_{t, \min }=0.04 \alpha_{H} m_{t} S_{D S} g$ 
Where $m_{\mathrm{t}}$ is total mass of podium and tower, $S_{\mathrm{DS}}$ is short-period design spectral acceleration coefficient, $g$ is gravitational acceleration, $\alpha_{\mathrm{H}}$ is a coefficient depending building height, $H_{\mathrm{N}}$.

Design Stage II: It covers assessment for Uninterrupted Occupancy (UO) performance objective under the effect of EGML-4 earthquakes, or assessment for Limited Damage (LD) performance objective under the effect of EGML-3 earthquake. Performance evaluations must be performed for UO performance objective with SBD principles, and limited damage performance objective with DBAD approach. Damping ratio of the system should be accepted as $2.5 \%$ in this phase.

Design Stage III: This is the final design stage. Design verification with nonlinear time history analysis must be performed under EGML-1 earthquake action. This stage covers providing of near collapse performance objective as normal performance target, or providing controlled damage performance objective as advanced performance target under the effect of EGML-1 earthquake. Some strain and internal force limits must be controlled.

The term "structural form systems" in structural engineering refers to lateral load-resisting system of a structure. Special regulations about how to design of lateral load-resisting systems of tall buildings are given in the special unit of TBEC2018[5]. Common structural form systems used in constructed with reinforced concrete and steel materials are shown in TBEC-2018[5]. Generally, a typical tall building consists of basement floors, podium and tower. Sometimes it consists of only a tower without podium. Load-bearing system of basement floors have rigid walls all around it. Mostly, the structural system of podium is consisting of frames and/or shear walls with or without flat slabs. The structural form of tower can be in different forms depending on its material. If reinforced concrete will be used, then a reinforced concrete core wall is existed with other vertical and horizontal elements. Frame elements having adequate rigidity and strength are existing around tube systems which elements ensures torsional rigidity to tube systems. Tall building structural systems in the earthquake zone should have regular structure, simple symmetrical plane and gradual change in elevation as far as possible. The stiffness of the building often comes from the walls of the core. The core is placed in the middle of the plan to minimize torsional stresses and enlarge lateral stiffening. Reinforced concrete shear walls are also used, when considering the stiffness of the building, because they are suitable to transfer the shear forces induced by lateral loads. The primary task for a structural design of a building is the absorption of horizontal loads and the capacity to transfer the resulting moment down into the foundation [16]. Improper selection of structural system will increase the potential risk of safety problems. Therefore, the optimization of the structural system is inevitable, the emerging of new materials and new technologies in construction sector also make it possible to optimization [17]. 
Table 2. Performance Objectives and Improvement/Design Approaches with respect to Earthquake Design Classes for tall buildings (Building height class is 1.0)

\begin{tabular}{|c|c|c|c|c|}
\hline & \multicolumn{2}{|c|}{$\mathrm{EDC}=1,2,3,3 \mathrm{a}, 4,4 \mathrm{a}$} & \multicolumn{2}{|l|}{$\mathrm{EDC}=1 \mathrm{a}, 2 \mathrm{a}$} \\
\hline & Normal & Improvement/ & Normal & Improvement \\
\hline & Performance & Design & Performance & Design \\
\hline EGML & Target & Approach & Target & Approach \\
\hline EGML-4 & UO & SBD & & \\
\hline EGML -3 & & & $\mathrm{IO}$ & DBAD \\
\hline EGML -2 & $\mathrm{CD}$ & SBD & $\mathrm{CD}$ & SBD \\
\hline EGML -1 & $\mathrm{NC}$ & DBAD & $\mathrm{CD}$ & DBAD \\
\hline \multicolumn{5}{|c|}{ Abbreviations: } \\
\hline \multicolumn{5}{|c|}{ UO: Uninterrupted Occupancy } \\
\hline \multicolumn{5}{|c|}{ IO: Immediate Occupancy } \\
\hline \multicolumn{5}{|c|}{ CD: Controlled Damage } \\
\hline \multicolumn{5}{|c|}{ NC: Near Collapse } \\
\hline \multicolumn{5}{|c|}{ SBD: Strength-Based Design } \\
\hline \multicolumn{5}{|c|}{ DBAD: Displacement-Based Assessment and Design } \\
\hline
\end{tabular}

Soil strata at the project site is another important factor on the seismic ground acceleration to which a building is subjected. Weaker strata amplify the intensity of ground acceleration at the surface, and low-frequency components of a seismic event are amplified in such soils. This is of particular concern to tall buildings with typically low fundamental frequencies. Liquefaction involves the consolidation of loose soils, in which the settlement occurs in a very short time, causing a sudden increase in pore-water pressure. As a result, effective stresses are reduced to zero and the soil effectively turns to liquid, with subsequent loss of bearing capacity [3]. Soil strata conditions and liquefaction risk should be analyzed before the design of a tall building. For a healthy foundation design, an extensive ground survey should be carried out at first, and the necessary data must be obtained by carefully from the field. In this context, a ground investigation supported by geological, hydrogeological and geotechnical researches should be carried out in the field. The engineering properties of the soil layers should be determined by in-situ experiments and a reliable geotechnical soil model should be established by completing the necessary laboratory studies. In design process of foundation, preliminary and final design steps should be followed, settlement analyzes should be performed, trial piles in the field should be constructed, and necessary experiments on site and laboratory should be made. Finally, a detailed report including all calculations and drawings should be prepared completely. Generally piled raft foundations which is subjected to a combination of vertical, lateral and overturning forces are preferred for tall buildings. The threedimensional frame in superstructure, its foundation and the soil, on which it rests, together constitute a complete system. The effect of soil-structure interaction becomes prominent for tall buildings. The design philosophy should be based on both ultimate load capacity and settlement criteria. TBEC-2018 [5] adopts performance-based design in design of foundations for tall building systems. According to TBEC-2018, a preliminary foundation design must be performed at the first design stage under the effect of EGML-2. Then a performance evaluation must be performed at third design 
stage under the effect of EGML-1. The internal forces and deformations that will be used in this evaluation must be determined from time history analysis of the model. In the third stage, the calculations of the structure-pile-ground dynamic interaction should be done to cover the kinematic interaction between the ground environment and the piles under the earthquake ground motion defined in the basement rock. At the same time, it should be such that it covers the inertial interaction under the effects transferred from the superstructure to the ground-pile system. For these, the methods described in section 16.10 of the code should be used. The following issues usually need to be addressed in the design of foundations for tall buildings [18]:

$>$ Ultimate capacity of the foundation

$>$ Cyclic nature of wind and earthquake loadings

$>$ Differential and overall settlements

$>$ Structural design of the foundation system

$>$ Possible effects of externally-imposed ground movements on the foundation system

$>$ Earthquake effects

$>$ Dynamic response of the structure-foundation system to wind-induced forces.

\section{Conclusion}

Tall buildings have become one of the indispensable building types of our age. Because of their height, they have many design challenges that distinguish tall buildings from other low-rise or middle-rise buildings. A critical review is presented in this study about structural forms, wind and earthquake effects. Also, the new Turkish national earthquake code regulation for tall buildings is considered. There were no special provisions for tall buildings in the repealed Turkish Earthquake Code-2007 [19]. Therefore, tall building design teams encountered several problems in the past. After 2018, the renewed TBEC-2018 has included a special chapter for tall buildings. The renewed code follows the performance based design approach which is a modern approach used in many national and international earthquake codes.

Wind effect is another very important effect that should be considered as much as earthquake effect, and even sometimes wind effect is more critical than earthquake effect for tall buildings. The effect of wind on the tall buildings are very complex compared to the low-rise structures, just like the earthquake effects. The issues requiring special expertise, wind forces and their effects on human comfort are discussed. In addition, the wind has important effects on the nonstructural elements of the building, such as the facade cladding, and should be taken into account in the structural and architectural design phases. Special code provisions against for strong wind actions for tall buildings at the national level do not yet exist in Turkey. Therefore, other countries' regulations or international regulations such as Eurocode should be followed. 


\section{References}

[1] CTBUH, Council on Tall Buildings and Urban Habitat, Illinois Institute of Technology, S.R. Crown Hall, 3360 South State Street, Chicago, Illinois, USA, www.ctbuh.org.

[2] Büyüköztürk, O., Güneş O. (2004). High-Rise Buildings: Evolution and Innovations, https://studylib.net/doc/14854814/high-rise-buildings--evolution-and-innovations-dr.-oral-b... [Accessed: 07 June 2019]

[3] fib Task Group 1.6 (2014). Tall Buildings. MPA The Concrete Centre and Fédération internationale du béton (fib), London, 1st Edition, 160 p. ISBN 978-1-908257-14-7.

[4] Emporis, Emporis Corporation, A Global Building Information Company, Theodor-Heuss-Allee 2, 60486 Frankfurt, Germany, www.emporis.com.

[5] Turkish Building Earthquake Code (TBEC-2018), Republic of Turkey, Disaster and Emergency Management Authority, 2018 (in Turkish)

[6] Günel M.H, Ilgın H. (2014). Tall Buildings: Structural Systems and Aerodynamic Form, Rootledge Taylor and Francis Group, London, 1st Edition, 214 p. ISBN-13: 978-1138021778.

[7] Akbar R. T. (2014). Tall and Supertall Buildings: Planning and Design, McGraw-Hill Education, New York, 1st Edition, 416 p. ISBN: 9780071818711

[8] Taranath, B.S. (2010). Reinforced Concrete Design of Tall Buildings, CRC Press, New York, 1st Edition, 989 p. ISBN 9781439804803

[9] Paltun, S., Gültekin, A.B., Çelebi, G. (2015). Investigation of Formal Structure of Building Aerodynamics: Relationship of Building Form and Wind, 2nd International Sustainable Building Symposium, Ankara, Turkey, 28 - 30th May 2015, pp.432-439.

[10] Semizoğlu, R. (2009). Rüzgar Türbinlerinin Gökdelen Mimarisine Etkisinin Tipolojik İncelenmesi, Yüksek Lisans Tezi, Yıldız Teknik Üniversitesi Fen Bilimleri Enstitüsü, İstanbul, Turkey, 77 p. (in Turkish)

[11] Kim H., Shin S. (2014). Reduction of Differential Column Shortening in Tall Buildings. International Journal of Civil, Environmental, Structural, Construction and Architectural Engineering, 8(2): 145-148.

[12] Ilgın H.E., Günel M.H. (2007). The Role of Aerodynamic Modifications In The Form of Tall Buildings Against Wind Excitation, METU Journal of The Faculty of Architecture, 24(2):17-25.

[13] Şafak E. (2012). Yüksek Yapılardaki Rüzgar Yüklerinin Hesabı. İMO Türkiye Mühendislik Haberleri, 471(1): 27-38. (in Turkish).

[14] Kayvani, K. (2014). Design of High-Rise Buildings: Past, Present and Future, 23rd Australasian Conference on the Mechanics of Structures and Materials (ACMSM23), Southern Cross University, Lismore, Australia, 9-12 December 2014, pp. 15-20

[15] Willford, M. (2006). Recommendations for the Seismic Design of High-Rise Buildings. https://global.ctbuh.org/resources/papers/download/429-ctbuh-recommendations-for-the-seismic-design-ofhigh-rise-buildings.pdf. [Accessed:05 June 2019]

[16] Grünbaum C. (2008). Structures of tall buildings, Report TVBK - 5156, Department of Structural Engineering, Lund Institute of Technology, Sweden.

[17] Jingyuan M., Fu M., Chensuo H., Zhixian W. (2013). Seismic Design of the High-Rise Building Structure and Sustainable Development. Applied Mechanics and Materials, 351-352: 536-540. 
[18] Poulos H.G. (2010). The Design of Foundations for High-Rise Building. Proceedings of ICE Civil Engineering, 163: 27-32.

[19] TEC-2007-Turkish Earthquake-resistant Code, Specification for Buildings to Be Built in Seismic Zones, Ministry of Public Works and Settlement, Ankara, Turkey, (in Turkish). 